\title{
Nueva legislación sobre la protección de los animales utilizados en investigación
}

Patri Vergara ${ }^{1}$

La utilización de animales en la investigación biomédica encuentra a menudo en la sociedad posiciones encontradas y difíciles de satisfacer a la vez. Por una parte la sociedad mayoritariamente demanda más y mejores tratamientos para las enfermedades que afectan a las personas o a los animales con los que convive y, por otra, una sociedad que llamamos desarrollada ha de considerar el sufrimiento animal como algo a minimizar, o mejor, a eliminar por completo.

Sin entrar en polémica, la sociedad no ve en estos momentos factible suprimir la investigación con animales sin que se resientan de forma muy significativa los avances en biomedicina. Para ejemplos de cómo la investigación con animales permite el avance en el desarrollo de nuevos tratamientos se puede visitar la web ${ }^{2}$. Sin olvidar que la protección de los derechos y la seguridad de las personas ha llevado al desarrollo de Principios como el de la Declaración de Helsinki ${ }^{3}$ o Ethical Principles for Medical Research Involving Human Subjects que condiciona la investigación con seres humanos o el tratamiento con nuevos fármacos a que la seguridad de las personas esté garantizada, incluso si es apropiado, mediante la utilización de animales.

\footnotetext{
${ }^{1}$ Veterinaria y Catedrática de Fisiología Animal de la Universitat Autònoma de Barcelona. Actualmente preside el International Council for Laboratory Animal Science (ICLAS) y es responsable del Máster en Ciencia y Bienestar del Animal de Laboratorio de la UAB.

2 http://www.fbresearch.org/

${ }^{3}$ http://www.who.int/bulletin/archives/79(4)373.pdf
} 
Por otra parte, ya en los años 50 del pasado siglo algunos científicos y sociedades científicas (algunas incluso ya a finales del siglo XIX) definieron lo que deberían ser los principios éticos que rigiesen el uso de animales en investigación. En particular el principio que conocemos como de las 3Rs (Reemplazo (no utilizar animales si no es estrictamente necesario), Reducción (utilizar el menor número posible) y Refinamiento (buscar continuamente métodos y modelos en los que podamos obtener los mismos resultados, o muy a menudo mejores, con un menor sufrimiento animal) ha sido universalmente aceptado y se encuentra recogido específicamente en toda la legislación para la protección de los animales utilizados en investigación.

Mucho más recientemente científicos y científicas de todas las áreas de las ciencias han firmado una declaración en defensa de la utilización de los animales en investigación conocida como la Declaración de Basilea ${ }^{4}$ por haberse firmado en esta ciudad suiza. Esta declaración compromete a los investigadores e instituciones firmantes a cumplir con el principio de las 3 Rs, a planificar los experimentos que requieran el uso de animales con extremo cuidado y a ser transparentes en lo que concierne a la utilización de animales en investigación.

Legislación sobre protección de los animales utilizados en investigación biomédica

La utilización de animales para obtener avances en la investigación biomédica está sometida en el ámbito de la Unión Europea a una estricta regulación para garantizar el bienestar de los animales desde la publicación de la Directiva 86/609/EEC.

\footnotetext{
${ }^{4}$ http://www.basel-declaration.org/
} 
Esta legislación exigía entre otras cosas: a) la implementación del Principio de las 3Rs; b) que los animales fuesen mantenidos en instalaciones adecuadas; c) en las especies más comunes en centros registrados cuya finalidad era únicamente la cría de animales para investigación; d) el que las personas que trabajan y utilizan animales estuviesen formados para ello y e) que además se publicasen estadísticas fiables de los animales que se utilizaban y la finalidad para la que eran usados.

Tras varios años de debate para su actualización ésta se produjo con la publicación de la Directiva 010/63/EU en el año 2010. La nueva directiva recoge además la revisión del Apéndice A de la Convención Europea ETS 123 que revisa las condiciones de mantenimiento y estabulación de las especies más comunes utilizadas en investigación.

España como país de la Unión Europea ya había recogido en su legislación la Directiva de 1986 aunque con un desarrollo desigual en las diferentes Comunidades Autónomas. La Directiva 2010 ha sido recientemente traspuesta en el Decreto $53 / 2013^{5}$ de 1 de febrero, que a lo largo de este año esperamos que sea asumido por las Comunidades Autónomas.

¿Qué representa esta nueva legislación con respecto a la anterior? Como todos los cambios supone un reto y creará discusiones y dificultades en su aplicación pero, en resumen, no reduce en ningún caso la protección ya conseguida sino que mejora y desarrolla otros aspectos:

1) Reconoce la contribución necesaria de los animales al avance de la investigación biomédica para conseguir mayores cotas de bienestar de las personas y de los animales.

\footnotetext{
${ }^{5}$ http://www.boe.es/boe/dias/2013/02/08/pdfs/BOE-A-2013-1337.pdf
} 
2) Incluye especies que hasta ahora no estaban incluidas para su protección, abriendo el espectro a formas fetales y a los cefalópodos que son el primer grupo de invertebrados acogidos para su protección.

3) Limita de forma más clara la utilización de primates no humanos y particularmente la de los grandes simios. Aunque se incluye una clausula de salvaguarda gracias a la cual se podría ampliar su utilización en caso de circunstancias excepcionales tanto para la especie humana como para ellos mismos.

4) Establece que todos los proyectos donde se proponga la utilización de animales tengan que superar una evaluación ética y que tengan una supervisión que garantice a los animales su bienestar y su salud.

5) Obliga a definir el grado de severidad de cada procedimiento y a su evaluación retrospectiva para establecer la severidad real con el objetivo de refinar métodos y procedimientos para reducirla.

6) Obliga a la preparación de resúmenes no técnicos de los proyectos que serán públicos.

7) Impone la creación de centros para el desarrollo de alternativas a la experimentación animal. 